(c) American Dairy Science Association, 2005.

\title{
In Vitro Production of Holstein Embryos Using Sex-Sorted Sperm and Oocytes from Selected Cull Cows
}

\author{
R. D. Wilson, ${ }^{1}$ K. A. Weigel, ${ }^{1}$ P. M. Fricke, ${ }^{1}$ J. J. Rutledge, ${ }^{2,3}$ M. L. Leibfried-Rutledge, ${ }^{3}$ \\ D. L. Matthews, ${ }^{2}$ and V. R. Schutzkus ${ }^{1}$ \\ ${ }^{1}$ Department of Dairy Science, and \\ ${ }^{2}$ Department of Animal Sciences, University of Wisconsin-Madison, Madison 53706 \\ ${ }^{3}$ BOMED, Inc., 2433 University Avenue, Madison, WI, 53726
}

\begin{abstract}
The objective of this study was to explore potential synergies between sex-sorted sperm and in vitro embryo production for generating replacement heifers on commercial dairy farms. Selected involuntary cull cows (i.e., genetically suitable cows that were culled due to injury, illness, or infertility) from 7 Wisconsin farms were used as donors, and ovaries were collected via colpotomy or at the time of slaughter. Oocytes were aspirated, fertilized in vitro with sex-sorted sperm 22 $\pm 0.2 \mathrm{~h}$ later, cultured, matured for 7 to $8 \mathrm{~d}$, and transferred into recipient cows and heifers on the farms from which the cull cows originated. From August 2002 to June 2003, ovaries were recovered from 104 Holstein donors. Sex-sorted sperm from 3 Holstein sires (obtained via fluorescence-activated cell sorting) were used. A total of 365 transferable embryos were produced, an average of $3.6 \pm 0.3$ per donor. However, due to limited availability of recipient animals, only 272 (fresh) embryos were transferred, an average of $2.6 \pm$ 0.3 per donor. A random subset of recipients received an injection (i.m.) of $\mathrm{GnRH}(100 \mu \mathrm{g})$ at the time of embryo transfer. When lactating cows were used as recipients, mean conception rates were $16.3 \%$ for recipients identified based on standing estrus and $20.0 \%$ for recipients synchronized using a timed breeding program (Ovsynch). Conception rates for in vitro-produced embryos were lower than corresponding conception rates for control cows inseminated using unsorted semen. When virgin heifers were used as embryo recipients (all standing estrus), the mean conception rate was $34.2 \%$. The following effects significantly impacted conception rate: farm, season, recipient group (cow vs. heifer), sire of embryo, and GnRH injection. Of 40 fullterm calves generated using sex-sorted semen, 37 were female. These results suggest that "low-cost" in vitro embryo production using cull cows as donors, in con-
\end{abstract}

Received August 3, 2004.

Accepted September 28, 2004.

Corresponding author: Kent Weigel; e-mail: kweigel@wisc.edu. junction with sex-sorted sperm, could be an effective tool in dairy cattle breeding programs, but only if conception rates can be improved.

(Key words: sperm sexing, in vitro fertilization, dairy)

Abbreviation key: AIPL = USDA Animal Improvement Programs Laboratory, ET = embryo transfer, IVP = in vitro production, $\mathbf{M E}=$ mature equivalent, TAI $=$ timed artificial insemination.

\section{INTRODUCTION}

Separating bovine sperm into X- and Y-bearing fractions has been of keen interest to scientists for decades. Several reviews have addressed the possibilities, limitations, and potential applications of this technology (Hohenboken, 1999; Seidel et al. 1999; Seidel, 2002; Seidel et al., 2002; Weigel, 2003). Isolation of X-bearing sperm, in particular, could have important consequences with respect to the availability and affordability of replacement dairy heifers. Van Vleck et al. (1981, 1976) speculated that farmers could achieve financial benefits even if the cost of sex-sorted semen was twice that of unsorted semen from a comparable sire. At present, the only proven method for sexing sperm is the fluorescence-activated cell sorting approach of Johnson et al. (1987a, 1987b, 1989, 1999, and 2000). Commonly known as the "Beltsville sperm sexing technology," the method takes advantage of a 3.8\% difference in DNA content between X-and Y-bearing bovine sperm. However, limitations in the speed and efficiency of the process, coupled with adverse effects on in vivo conception rates, have largely prevented cost-effective implementation of this technology on commercial dairy farms (Amman, 1999).

Widespread, cost-effective implementation of systems for in vitro production (IVP) of bovine embryos has also been limited by costs, inefficiencies, and compromised conception rates. However, IVP and sperm sorting may have synergies that would allow these technologies to be combined effectively in modern breeding programs. In particular, IVP requires fewer sperm than conventional AI, thereby negating concerns about the 
cost and availability of sexed semen. In turn, the efficiency of IVP programs could be enhanced dramatically by skewing the sex ratio in favor of females (without the cost, waste, and compromised conception rate associated with embryo biopsy). Faber (2003) and Amman et al. (1999) discussed the potential of sex-sorted sperm with respect to the needs and limitations of IVP programs. Widespread commercial implementation of these technologies will only be achieved through development of cost-effective breeding programs that can be integrated into the routine management of dairy operations. An intriguing low-cost option is to use known, selected cull cows (cows with acceptable genetic merit that suffer from injury, illness, or infertility) or anonymous cull cows (randomly chosen cows from a commercial abattoir) as IVP donors. Such programs could be cost-effective and commercially viable, provided that the timing of ova recovery and embryo transfer (ET) can be successfully matched with the controlled breeding programs of the participating farms.

The objective of this research was to assess potential synergies between IVP and semen-sorting technologies for creating high quality dairy replacement heifers in a cost-effective manner. Specific goals included: 1) quantifying the number of transferable embryos that can be generated from a cull cow using sex-sorted sperm; 2) assessing the conception rates that can be achieved by using cow or heifer recipients; 3) identifying key environmental factors related to success of the system (e.g., farm, season, sire, GnRH injection); 4) collecting calving data (sex ratio, calving ease, late term abortions), and 5) measuring the genetic superiority (or inferiority) of the selected donors.

\section{MATERIALS AND METHODS}

Seven commercial dairy farms in Wisconsin that were within $150 \mathrm{~km}$ of the collaborating IVP laboratory (BOMED, Inc., Madison, WI) were chosen as collaborators. Each farmer selected several potential IVP donors from the pool of animals to be culled each month based on their genetic merit and phenotypic performance. Virtually all donors were "involuntary culls", i.e., productive, profitable cows whose removal from the herd was forced due to illness, injury, or infertility. Between August 2002 and June 2003, ovaries were recovered from 104 Holstein donors supplied by these cooperating farms. Initially (August-October 2002), ovaries were retrieved surgically (via colpotomy) on the farm, such that the farmers could continue to milk these cows until the end of lactation. However, because almost all cows were sent to slaughter within a few weeks after surgery, we changed the protocol so that ovaries were recovered at the time of slaughter during the remainder of the study (November 2002 - June 2003).

On each farm, the schedule for shipping cows to the cooperating commercial abattoir was aligned with the farm's existing schedule for synchronization of ovulation or estrus, as shown in Figure 1. Therefore, the routine reproductive management program of each herd was uninterrupted, except that some of the synchronized cows were held an extra 7 or $8 \mathrm{~d}$ as potential recipients, rather than receiving timed artificial insemination (TAI) using unsorted semen. Following recovery via colpotomy or at the time of slaughter, ovaries from each donor were labeled and stored individually at room temperature until all donors from that farm were processed (typically 1 to $2 \mathrm{~h}$ ). Ovaries were then transported directly to the cooperating IVP laboratory (BOMED, Inc., Madison, WI) for aspiration of oocytes and IVP of embryos.

Sex-sorted (X-bearing) sperm from 3 young Holstein sires was used. These sires were part of an AI progeny testing program (Accelerated Genetics, Baraboo, WI), and their semen had previously been collected and sorted at 50 psi by XY, Inc. (Fort Collins, CO), using the fluorescence-activated cell sorting (Beltsville) method. Farmers were initially allowed to choose which sire would be used for IVP on a given day, but their choices were restricted in the latter months of the study to achieve balanced usage of these sires. Details regarding the IVP procedure and culture system used in this study were reported previously by Wilson et al. (accepted).

On d 7 or 8 of culture (where d 0 refers to the day of fertilization in the IVP laboratory), embryos were transported back to their respective cooperating farms and were transferred (fresh) into recipient Holstein cows or heifers. Recipients were either synchronized using the Ovsynch program (Pursley et al., 1995) or identified based on visible signs of estrus. All recipients were palpated to verify the presence and quality of a corpus luteum on the day of embryo transfer. Arnett et al. (2002) reported, with limited numbers, an increase in conception rate when GnRH was administered at the time of transfer. Therefore, from January to June 2003 half of the recipient animals were selected randomly to receive an intramuscular injection of $\mathrm{GnRH}$ (100 $\mu \mathrm{g}$; Fertagyl, Intervet, Inc., Millsboro, DE) at the time of embryo transfer. When the number of available recipients exceeded the number of transferable embryos, recipients were chosen at random. When the number of transferable embryos exceeded the number of available recipients, the highest quality (grade 1) embryos were transferred first. Depending on the preference of the individual farmer, the remaining embryos were either: 1) discarded; 2) transferred into extra recipients on another cooperating farm ( 2 farms had the 


\begin{tabular}{|c|c|c|c|c|c|c|}
\hline & & Monday & Tuesday & Wednesday & Thursday & Friday \\
\hline \multirow{2}{*}{ Week 1} & Donors & & & & & \\
\hline & Recipients & 1st GnRII & & & & \\
\hline \multirow{2}{*}{ Week 2} & Donors & & & $\begin{array}{c}\text { Harvest ovaries } \\
\text { (by colpotomy or } \\
\text { at abattoir) }\end{array}$ & Fertilize oocytes & \\
\hline & Recipients & $\mathbf{P G F}_{2 \alpha}$ & & 2nd GnRH & $\begin{array}{l}\text { Timed AI controls } \\
\text { Hold recipients }\end{array}$ & \\
\hline \multirow{2}{*}{ Week 3} & Donors & & & & & \\
\hline & Recipients & & & & $\begin{array}{l}\text { Embryo transfer } \\
\text { GnRH to randomly } \\
\text { chosen recipients }\end{array}$ & \\
\hline
\end{tabular}

Figure 1. Schedule for collection of ovaries, fertilization of oocytes, and transfer of in vitro produced (IVP) embryos on an example cooperator farm.

same collection and transfer schedule), or 3) an additional embryo was transferred (contralateral) into an existing recipient on the same farm (i.e., a "twin transfer").

Data were collected primarily from on-farm management software programs (e.g., DairyComp 305, Tulare, $\mathrm{CA}$ ), and calving ease scores were assessed and recorded by each individual farmer. When comparing conception rates of embryo recipients and AI controls, all animals inseminated $7 \mathrm{~d}$ before the embryo transfers on a given farm were considered as contemporaries. Data regarding lactation number, DIM, and 305-d mature equivalent (ME) milk, fat, and protein yield were provided by AgSource (Verona, WI), and PTA values of donors and recipients were provided by the USDA Animal Improvement Programs Laboratory (AIPL). When comparing the genetic level of donors, recipients, and their herdmates, all animals milking in a given herd in same month as the ovary collection were considered as contemporaries.

Our statistical analysis of conception rates achieved with conventional AI (standing heat) or TAI vs. rates achieved with transfer of IVP embryos from sex-sorted sperm was based on logistic regression (Logistic procedure, SAS Institute Inc., Cary, NC). Explanatory factors included: embryo stage, synchrony of recipient, corpus luteum quality, corpus luteum side, amount of time the embryo was kept in the straw, farm, recipient group (lactating cow vs. virgin heifer), GnRH treatment at embryo transfer, season, and sire of embryo. Backward, stepwise elimination of variables was used to construct the final model for analysis; this model included the effects of treatment (AI with unsexed semen vs. transfer of IVP embryo), farm, and recipient group (cow vs. heifer). A similar model, with the treatment effect excluded, was applied to data from IVP embryo transfers only to assess differences in conception rates by farm, season, recipient group, GnRH injection group, and sire of embryo.

\section{RESULTS AND DISCUSSION}

A summary of oocyte and embryo yields per donor, as well as genetic and phenotypic merit of the donors and the recipients, is given in Table 1 . Ovaries were collected from 104 donor animals; 6 were yearling heifers that were culled due to reproductive failure, and the rest were lactating cows. Mean age of the donors was $4.9 \mathrm{yr}$, and mean age of the recipients was $2.7 \mathrm{yr}$ (165 were lactating cows and 76 were yearling heifers).

On average, 33.9 oocytes were recovered per donor animal, and these oocytes led to the production of 3.6 transferable embryos per donor. However, due to limited availability of recipients for fresh embryos on certain days, only 2.6 embryos per donor were transferred. Controlling variability in the number of transferable IVP embryos produced on a given day and, hence the number of required recipients, is a key challenge. Culling a larger number of donors at one time (perhaps 10 to 15 animals from several farms that are willing to 
Table 1. Summary of oocyte and embryo yields per donor, as well as age, mature equivalent (ME) milk production, and genetic merit of donors and recipients used in this study.

\begin{tabular}{llrlr}
\hline & $\begin{array}{l}\text { No. of } \\
\text { donors }\end{array}$ & Mean \pm SEM & $\begin{array}{l}\text { No. of } \\
\text { recipients }\end{array}$ & Mean \pm SEM \\
\hline Heifers & 6 & $\ldots$ & 76 & $\ldots$ \\
Cows & 98 & $\ldots$ & 165 & $\ldots$ \\
Age (yr) & 104 & $4.9 \pm 0.2$ & 240 & $2.7 \pm 0.1$ \\
No. of oocytes collected per donor & 104 & $33.9 \pm 3.3$ & $\ldots$ & $\ldots$ \\
No. of embryos produced per donor & 104 & $3.6 \pm 0.3$ & $\ldots$ & $\ldots$ \\
No. of embryos transferred per donor & 104 & $2.6 \pm 0.3$ & $\ldots$ & $207 \pm 11$ \\
Days in milk & 89 & $380 \pm 19$ & 130 & $2.1 \pm 0.1$ \\
Lactation number & 89 & $2.9 \pm 0.2$ & 130 & $13,155 \pm 232$ \\
305-d ME milk (kg) & 89 & $13,259 \pm 369$ & 130 & $458 \pm 8$ \\
305-d ME fat (kg) & 89 & $465 \pm 13$ & 130 & $384 \pm 6$ \\
305-d ME protein $(\mathrm{kg})$ & 89 & $384 \pm 11$ & 130 & $464 \pm 64$ \\
PTA Milk & 74 & $436 \pm 72$ & 103 & $13 \pm 2$ \\
PTA Fat & 74 & $14 \pm 3$ & 103 & $16 \pm 2$ \\
PTA Protein & 74 & $14 \pm 2$ & 103 & $130 \pm 13$ \\
Lifetime Net Merit $(\$)$ & 74 & $122 \pm 17$ & 103 & $\ldots$ \\
\hline
\end{tabular}

share recipients) would be preferable in practice. Details regarding embryo development rates, including comparisons with unsorted sperm, were reported by Wilson et al. (accepted).

As shown in Table 1, most donor cows were in late lactation (380 d postpartum, on average). Average 305d ME milk, fat, and protein yield of donors was high ( $>13,000 \mathrm{~kg}$ of milk/lactation), but phenotypic differences between donors and recipients on these farms were negligible. Only $83 \%$ of donors and $79 \%$ of recipients had PTA information available from USDA-AIPL; the rest were excluded from the national genetic evaluation due to errors in identification or performance data. Average PTA for milk, fat, protein, and Lifetime Net Merit were very similar for donors and recipients. The lack of genetic superiority among donor animals, relative to recipients, could be the result of several factors. First, the farmers may not have been very selective when choosing donors from the pool of available cull cows. Second, farmers may have chosen donors based on other criteria, such as type traits. Third, because recipient animals were, on average, more than $2 \mathrm{yr}$ younger than donors, the genetic trend in milk production (about $45 \mathrm{~kg}$ PTA milk/yr in Holsteins) may have offset the selection differential between donors and recipients. On the other hand, it is reassuring to note that, despite the fact that these donors were "cull cows", their genetic merit and phenotypic performance was on par with animals that were kept as recipients. Therefore, farmers should not expect to sacrifice genetic progress in such schemes, although many would be willing to do so for an increase in the percentage of heifer calves born. It should also be noted that the 3 young Holstein sires used in this study have now completed progeny testing and have Lifetime Net Merit values of $\$ 379$, $\$ 276$, and $\$ 318$ (based on February 2004 AIPL genetic evaluation results). In practice, it would be desirable to use sex-sorted sperm from elite proven sires, but such semen was unavailable at the time of this study.

A summary of lactation performance and reproductive efficiency on the seven cooperating commercial dairy farms is shown in Table 2. Herd size ranged from 246 to 1650 cows, and 305-d ME milk production was exceptionally high, averaging $13,279 \mathrm{~kg} / \mathrm{cow}$. Reproductive performance varied among farms, with herds ranging from 140 to 197 for mean days open and 215 to 256 for mean DIM. Overall, these were well-managed commercial dairies with a strong focus on achieving high milk production.

Table 3 shows the overall mean conception rates for IVP embryos and AI controls, as well as mean conception rates according to recipient group (heifers, synchronized cows, or standing estrus cows). Table 3 also shows the results of significance tests for differences in conception rate based on a logistic regression model that included the effects of treatment (IVP embryo vs. AI control) and recipient group (heifers, synchronized cows, or standing estrus cows). The overall mean conception rate for IVP embryos $(24.3 \%)$ was lower $(P<0.05)$ than that of AI controls $(36.1 \%)$. Although the difference in average conception rate between yearling heifers inseminated by AI after a standing estrus $(50.0 \%)$ and cows inseminated by AI (33.8\%) was even greater, this result was not statistically significant (due to the limited number of control heifers with pregnancy examination data). As expected (Sartori et al., 2002), conception rates for both IVP embryos and AI semen were higher $(P<0.05)$ for yearling heifers than for lactating cows, although the number of control heifers included was low. Interestingly, cows that were inseminated using TAI after synchronization of ovulation had a slightly higher (though not statistically significant) mean con- 
Table 2. Mean ( \pm SEM) for lactation performance and reproductive efficiency on the farms that participated in this study.

\begin{tabular}{lccccccc}
\hline & Farm A & Farm B & Farm C & Farm D & Farm E & Farm F & Farm G \\
\hline Herd Size & 881 & 527 & $243 \pm 6$ & 246 & 1650 & 715 & 309 \\
Days in milk & $253 \pm 5$ & $243 \pm 7$ & $238 \pm 3$ & $251 \pm 5$ & $256 \pm 5$ & 463 \\
Lactation number & $2.4 \pm 0.04$ & $2.3 \pm 0.05$ & $3.1 \pm 0.09$ & $2.1 \pm 0.02$ & $1.9 \pm 0.03$ & $2.1 \pm 0.04$ & $2.3 \pm 0.04$ \\
Days open (n) & $157 \pm 3$ & $184 \pm 5$ & $144 \pm 4$ & $146 \pm 2$ & $189 \pm 11$ & $197 \pm 5$ & $140 \pm 3$ \\
305-d Milk (kg) & $13,946 \pm 88$ & $15,385 \pm 110$ & $11,878 \pm 146$ & $12,809 \pm 71$ & $13,207 \pm 96$ & $12,207 \pm 136$ & $13,518 \pm 109$ \\
305-d Fat (kg) & $459 \pm 3.2$ & $545 \pm 4.5$ & $444 \pm 5.0$ & $455 \pm 2.3$ & $481 \pm 3.6$ & $442 \pm 5.0$ & $512 \pm 4.1$ \\
305-d Protein (kg) & $405 \pm 2.7$ & $444 \pm 2.7$ & $347 \pm 4.1$ & $386 \pm 2.3$ & $392 \pm 2.7$ & $347 \pm 3.6$ & $393 \pm 3.2$ \\
\hline
\end{tabular}

ception rate than cows inseminated after a standing estrus, and a similar trend was observed in conception rates for IVP embryos.

Table 4 summarizes conception rates for IVP embryos and $\mathrm{AI}$ controls on each of the 7 cooperating farms. The number of donors per farm ranged widely (from 2 to 25). Three farms had mean conception rates for IVP embryos $\geq 23.7 \%$, although mean conception rates for IVP embryos ranged from 0.0 to $37.7 \%$ between farms (8.7 to $37.7 \%$ for farms with $\geq 20$ transfers). Mean conception rates for AI controls ranged from 19.2 to $60.0 \%$ (19.2 to $44.9 \%$ for farms with $\geq 50$ inseminations). Based on the logistic regression analyses, farms differed $(P<$ 0.05 ) in mean conception rates for both IVP embryos and AI controls.

Mean conception rates for IVP embryos according to GnRH treatment (or lack thereof) at the time of embryo transfer, season, and sire of embryo are shown in Table 5 , along with tests of significance based on a logistic regression model that included the effects of farm, recipient group (heifers, standing heat cows, or synchronized cows), GnRH treatment at embryo transfer, season, and sire of embryo. Injection of GnRH to randomly chosen recipients began in January 2003, so data from only the last 124 transfers (in January to June 2003) were

Table 3. Mean conception rate for in vitro produced (IVP) embryos or conventional AI according to type of recipient. Tests of significance were based on logistic regression of the outcome of each insemination or transfer event on farm, treatment, and recipient group.

\begin{tabular}{lll}
\hline & $\begin{array}{l}\text { IVP Embryos } \\
(\%)\end{array}$ & $\begin{array}{l}\text { AI Controls } \\
(\%)\end{array}$ \\
\hline Heifers - Standing heat & $34.2^{\mathrm{a}}$ & $50.0^{\mathrm{a}}$ \\
& $(26 / 76)$ & $(3 / 6)$ \\
Cows - Standing heat & $16.3^{\mathrm{b}}$ & $30.7^{\mathrm{a}}$ \\
& $(7 / 43)$ & $(23 / 75)$ \\
Cows - Synchronized & $20.0^{\mathrm{b}}$ & $36.8^{\mathrm{a}}$ \\
& $(19 / 95)$ & $(166 / 451)$ \\
Totals & $24.3^{\mathrm{d}}$ & $36.1^{\mathrm{c}}$ \\
& $(52 / 214)$ & $(192 / 532)$ \\
\hline
\end{tabular}

\footnotetext{
${ }^{\mathrm{a}, \mathrm{b}}$ Within a column, proportions with different superscripts differ $(P<0.05)$.

${ }^{\mathrm{c}, \mathrm{d}}$ Within a row, proportions with different superscripts differ $(P<$ $0.05)$.
}

included in the analysis of its effects on conception rate. Despite limited data, a significant $(P<0.05)$ improvement in conception rate was observed in recipients that received GnRH at the time of embryo transfer; from 19.4 (without $\mathrm{GnRH}$ ) to $41.4 \%$ (with $\mathrm{GnRH}$ ) in heifers and from 14.3 (without $\mathrm{GnRH}$ ) to $27.6 \%$ (with $\mathrm{GnRH}$ ) in milking cows. Although these results should be confirmed in a larger study, they seem to confirm the results reported by Arnett et al. (2002) in beef cattle. Seasonal differences (March-May, June, SeptemberNovember, and December-February) were also significant $(P<0.05)$, but the number of observations within each season was limited. It is also important to note that the study was completed in June 2003, to avoid adverse effects of high ambient temperature and humidity (Stott et al., 1962; Gwazdauskas et al., 1975), so no transfers occurred in July or August. Differences $(P<0.05)$ between embryo sires were also observed, as the conception rate for embryos from sire $\mathrm{C}$ was significantly lower (22.7\%) than that of the other 2 sires ( $25.7 \%$, collectively). In a previous field study involving conventional AI of virgin heifers with sex-sorted sperm from the sires used in the present study (Accelerated Genetics), sire $\mathrm{C}$ had lower average conception rates for both sex-sorted and unsorted semen, compared with sires A and B.

Calving results are shown in Table 6. Of 40 calves, only 3 were males; the remaining 37 (92.5\%) were females. No twins occurred, because none of the double transfers resulted in a pregnancy. The sex ratio of calves resulting from IVP embryos with sex-sorted sperm in this study was similar to the sex ratio achieved by using sex-sorted semen in conventional AI programs (Seidel, 1999). Mean calving ease scores and gestation lengths were within the normal range for Holstein cows and heifers. However, one female calf was extremely large, with a dystocia score of 5 (surgical removal was required), and neither the calf nor its recipient dam survived. Five of the 8 abortions came after $\geq 5$ mo of gestation and, although the cause was unknown, the abortion rate for IVP embryos (12.5\%) appeared similar to that of AI pregnancies on these farms. 
Table 4. Mean conception rate for in vitro produced (IVP) embryos and conventional AI on each farm. Tests of significance were based on logistic regression of the outcome of each insemination or transfer event on treatment (IVP embryo vs. AI control), farm, and type of recipient.

\begin{tabular}{|c|c|c|c|c|c|c|c|}
\hline & Farm A & Farm B & Farm C & Farm D & Farm E & Farm F & Farm G \\
\hline No. of donors & 25 & 2 & 4 & 21 & 15 & 23 & 14 \\
\hline $\begin{array}{l}\text { Conception rate for IVP } \\
\text { embryos }(\%)\end{array}$ & $\begin{array}{l}23.7^{\mathrm{ab}} \\
(9 / 38)\end{array}$ & $\begin{array}{l}0.0^{\mathrm{b}} \\
(0 / 3)\end{array}$ & $\begin{array}{l}15.4^{\mathrm{ab}} \\
(2 / 13)\end{array}$ & $\begin{array}{l}27.8^{\mathrm{ab}} \\
(15 / 54)\end{array}$ & $\begin{array}{l}13.3^{\mathrm{ab}} \\
(4 / 30)\end{array}$ & $\begin{array}{l}37.7^{\mathrm{a}} \\
(20 / 53)\end{array}$ & $\begin{array}{r}8.7^{\mathrm{ab}} \\
(2 / 23)\end{array}$ \\
\hline $\begin{array}{l}\text { Conception rate for } \mathrm{AI} \\
\text { controls }(\%)\end{array}$ & $\begin{array}{l}34.0^{\mathrm{abc}} \\
(55 / 162)\end{array}$ & $\begin{array}{l}25.0^{\mathrm{bc}} \\
(2 / 8)\end{array}$ & $\begin{array}{l}60.0^{\mathrm{a}} \\
(6 / 10)\end{array}$ & $\begin{array}{l}44.9^{\mathrm{abc}} \\
(96 / 214)\end{array}$ & $\begin{array}{l}19.2^{\mathrm{c}} \\
(10 / 52)\end{array}$ & $\begin{array}{l}23.0^{\text {bc }} \\
(17 / 74)\end{array}$ & $\begin{array}{l}50.0^{\mathrm{ab}} \\
(6 / 12)\end{array}$ \\
\hline Totals (\%) & $32.0^{\mathrm{ab}}$ & $18.2^{\mathrm{ab}}$ & $34.8^{\mathrm{ab}}$ & $41.4^{\mathrm{a}}$ & $17.1^{\mathrm{b}}$ & $29.1^{\mathrm{ab}}$ & $22.9^{\mathrm{ab}}$ \\
\hline
\end{tabular}

${ }^{\mathrm{a}, \mathrm{b}, \mathrm{c}}$ Within a row, farms with different superscripts differ $(P<0.05)$.

\section{CONCLUSIONS}

Based on the results presented herein, sex-sorted semen (obtained via the Beltsville method) can be combined with IVP to produce inexpensive dairy replacement heifers. Each cull cow can produce nearly 4 trans-

Table 5. Mean conception rates for in vitro produced (IVP) embryos by GnRH treatment, season, and sire of embryo. Tests of significance were based on logistic regression of the outcome of each insemination or transfer event on farm, recipient group (heifers, standing heat cows, or synchronized cows), season, GnRH, and sire of embryo, which was applied only for overall conception rate.

\begin{tabular}{llll}
\hline & $\begin{array}{l}\text { Conception } \\
\text { rate in } \\
\text { heifers }\end{array}$ & $\begin{array}{l}\text { Conception } \\
\text { rate in } \\
\text { milking cows }\end{array}$ & $\begin{array}{l}\text { Overall } \\
\text { conception } \\
\text { rate }\end{array}$ \\
\cline { 2 - 4 } GnRH & & & \\
Yes & 41.4 & 27.6 & $34.5^{\mathrm{a}}$ \\
No & $(12 / 29)$ & $(8 / 29)$ & $(20 / 58)$ \\
Season & 19.4 & 14.3 & $16.7^{\mathrm{b}}$ \\
Fall & $(6 / 31)$ & $(5 / 35)$ & $(11 / 66)$ \\
Winter & 62.5 & 25.5 & $30.9^{\mathrm{c}}$ \\
& $(5 / 8)$ & $(12 / 47)$ & $(17 / 55)$ \\
Spring & 35.9 & 7.7 & $19.8^{\mathrm{d}}$ \\
& $(14 / 39)$ & $(4 / 52)$ & $(18 / 91)$ \\
Summer & 16.0 & 26.9 & $21.6^{\mathrm{e}}$ \\
& $(4 / 25)$ & $(7 / 26)$ & $(11 / 51)$ \\
Sire of embryo & 75.0 & 28.6 & $38.9^{\mathrm{d}}$ \\
Sire A & $(3 / 4)$ & $(4 / 14)$ & $(7 / 18)$ \\
& & & \\
Sire B & 34.3 & 22.2 & $27.5^{\mathrm{f}}$ \\
& $(12 / 35)$ & $(10 / 45)$ & $(22 / 80)$ \\
Sire C & 21.4 & 23.9 & $23.3^{\mathrm{f}}$ \\
& $(3 / 14)$ & $(11 / 46)$ & $(14 / 60)$ \\
\hline & 40.7 & 12.5 & $22.7^{\mathrm{g}}$ \\
& $(11 / 27)$ & $(6 / 48)$ & $(17 / 75)$ \\
\hline
\end{tabular}

\footnotetext{
${ }^{a, b}$ Within a column, GnRH treatments with different superscripts differ $(P<0.05)$

${ }^{\mathrm{c}, \mathrm{d}, \mathrm{e}}$ Within a column, seasons with different superscripts $\operatorname{differ}(P$ $<0.05)$.

f,gWithin a column, sires with different superscripts differ $(P<$ $0.05)$.
}

ferable embryos, and very few $(\leq 10 \%)$ are wasted when using sex-sorted sperm, as compared with embryo sexing via biopsy (where $50 \%$ are wasted). In most cases, the genetic potential of replacement heifers resulting from conventional ET and live donors (with or without embryo sexing) will be higher than that of heifers resulting from IVP, sex-sorted sperm, and spent donors. However, the latter group of heifers can be generated at a fraction of the cost of the former.

Conception rates are likely to be much lower than those achieved by conventional AI with unsorted semen, so it is unlikely that transferring IVP embryos into milking recipients will be cost-effective. However, it is important to note that semen in the present study were sorted at $50 \mathrm{psi}$, and recent studies by Seidel et al. (2003) and Suh and Seidel (2003) indicate that sorting semen at lower pressure (as is the practice today) can lead to considerably less sperm damage and, hence, higher conception rates. In addition, conception rates for IVP embryos transferred into dairy heifers, beef cows, or beef heifers will be substantially higher than those observed in milking dairy cows. The IVP and sperm-sorting technologies, although somewhat limited in commercial applicability when used alone, could play an important role in livestock breeding programs when used together. Slight modifications will be needed to optimize low-cost IVP systems before they can be used efficiently on commercial farms. In particular, cooperating farms should pool donor cows and recipient heifers and should share the resulting IVP embryos, such that the waste of transferable embryos can be

Table 6. Summary of calving results from in vitro produced (IVP) embryos.

\begin{tabular}{llll}
\hline Outcome & $\begin{array}{l}\text { No. of } \\
\text { calves }\end{array}$ & $\begin{array}{l}\text { Mean calving } \\
\text { ease score }\end{array}$ & $\begin{array}{l}\text { Mean gestation } \\
\text { length (d) }\end{array}$ \\
\hline Female & 37 & $1.2 \pm 0.1$ & $281 \pm 1.2$ \\
Male & 3 & $1.3 \pm 0.3$ & $282 \pm 2.0$ \\
Aborted & 8 & $\ldots$ & $\ldots$ \\
\hline
\end{tabular}


minimized. Although conception rates could be improved by using yearling heifers as recipients, beef cows may be preferred, because the risk of severe dystocia (in cases of "large calf syndrome") would be reduced, as would the economic value of any injured recipients. In addition, preliminary results suggest that GnRH treatment at the time of embryo transfer may improve conception rates. Several authors (e.g., Cran et al., 1993) have suggested that sorting frozen (and subsequently thawed) sperm would be an attractive alternative for IVP programs, because it would allow access to the best AI sires available (even if methodological inefficiencies preclude sorting large volumes of semen from these valuable bulls). Other approaches to tailoring the sorting process for IVP embryo systems should be investigated, as should alternative breeding programs (besides those described herein) for capitalizing on synergies between these technologies.

\section{ACKNOWLEDGMENTS}

Financial support was generously provided by the University of Wisconsin Office for Corporate Relations and the Wisconsin Department of Agriculture, Trade, and Consumer Protection. Semen was donated by Accelerated Genetics, Inc. and was sorted by XY, Inc.; BOMED, Inc. provided the in vitro embryo production system. Assistance was provided by Rick Monson, Dave Northey, and Milo Wiltbank. Special thanks should be given to 7 commercial dairy farms (Crave, Holterman, Keller, Larson, Rickert, Ruedinger, and Zwald) that graciously donated animals, time, and labor for this project.

\section{REFERENCES}

Amann, R. P. 1999. Issues affecting the commercialization of sexed sperm. Theriogenology 52:1441-1457.

Arnett, A. M., J. D. Rhinehart, J. D. Bailey, R. B. Hightshoe, and L. H. Anderson. 2002. Administration of gonadotropin-releasing hormone $(\mathrm{GnRH})$ on d 5 or 6 of the estrous cycle alters follicle dynamics and increases pregnancy rates in beef cattle. J. Anim. Sci. 80(Suppl 1):534. (Abstr.)

Cran, D. G., L. A. Johnson, N. G. A. Miller, D. Cochrane, and C. Polge. 1993. Production of calves following separation of X- and Y-chromosome bearing sperm and in vitro fertilization. Vet. Rec. 132:40-41.
Faber, D. C., J. A. Molina, C. L. Ohlrichs, D. F. Van der Zwaag, and L. B. Ferre. 2003. Commercialization of animal biotechnology. Theriogenology 59:125-138.

Gwazdauskas, F. C., C. J. Wilcox, and W. W. Thatcher. 1975. Environmental and management factors affecting conception rate in a subtropical environment. J. Dairy Sci. 58:88-92.

Hohenboken, W. D. 1999. Applications of sexed semen in cattle production. Theriogenology 52:1421-1433.

Johnson, L. A. 2000. Sexing mammalian sperm for the production of offspring: The state-of-the-art. Anim. Reprod. Sci. 60-61:93-107.

Johnson, L. A., J. P. Flook, and H. W. Hawk. 1989. Sex preselection in rabbits: Live births from X and Y sperm separated by DNA and cell sorting. Biol. Reprod. 41:199-203.

Johnson, L. A., J. P. Flook, and M. V. Look. 1987a. Flow cytometry of $\mathrm{X}$ and $\mathrm{Y}$ chromosome-bearing sperm for DNA using an improved preparation method and staining with Hoechst 33342. Gamete Res. 17:203-212.

Johnson, L. A., J. P. Flook, M. V. Look, and D. Pinkel. 1987b. Flow sorting of $\mathrm{X}$ and $\mathrm{Y}$ chromosome-bearing spermatozoa into two populations. Gamete Res. 16:1-9.

Johnson, L. A., G. R. Welch, and W. Rens. 1999. The Beltsville sperm sexing technology: High-speed sorting gives improved sperm output for in vitro fertilization and AI. J. Anim. Sci. 77:213-220.

Pursley, J. R., M. O. Mee, and M. C. Wiltbank. 1995. Synchronization of ovulation in dairy cows using $\mathrm{PGF}_{2 \alpha}$ and $\mathrm{GnRH}$. Theriogenology 44:915-923.

Sartori, R., R. Sartor-Bergfelt, S. A. Mertens, J. N. Guenther, J. J. Parrish, and M. C. Wiltbank. 2002. Fertilization and early embryonic development in heifers and lactating cows in summer and lactating and dry cows in winter. J. Dairy Sci. 85:2803-2812.

Seidel, G. E., Jr. 2002. Current status of sexing mammalian spermatozoa. Reproduction 124:733-743.

Seidel, G. E., Jr., Z. Brink, K. H. Lu, A. F. Flint, J. F. De La TorreSanchez, and T. K. Suh. 2002. Normality of calves produced from IVF with sexed sperm and culturing embryos with insulin. Theriogenology 57:754. (Abstr.)

Seidel, G. E., Jr., Z. Brink, and J. L. Schenk. 2003. Use of heterospermic insemination with fetal sex as the genetic marker to study fertility of sexed semen. Theriogenology 59:515. (Abstr.)

Seidel, G. E., Jr., J. L. Schenk, L. A. Herickhoff, S. P. Doyle, Z. Brink, and R. D. Green. 1999. Insemination of heifers with sexed sperm. Theriogenology 52:1407-1420.

Stott, G. H., and R. J. Williams. 1962. Causes of low breeding efficiency in dairy cattle associated with high seasonal temperatures. J. Dairy Sci. 45:1369-1375.

Suh, T. K., and G. E. Seidel, Jr. 2003. Pressure during flow sorting of bull sperm affects post-thaw motility characteristics. Theriogenology 59:516. (Abstr.)

Van Vleck, L. D. 1981. Potential genetic impact of artificial insemination, sex selection, embryo transfer, cloning, and selfing in dairy cattle. Pages 222-242 in New Technologies in Animal Breeding. B. G. Brackett, G. E. Seidel, Jr., and S. M. Seidel, ed. Academic Press, New York, NY.

Van Vleck, L. D., and R. W. Everett. 1976. Genetic value of sexed semen to produce dairy heifers. J. Dairy Sci. 59:1802-1807.

Weigel, K. A. 2004. Exploring the impact of sexed semen on dairy cattle improvement programs. J. Dairy Sci. 87:E120-E130.

Wilson, R. D., P. M. Fricke, M. L. Leibfried-Rutledge, J. J. Rutledge, C. M. Syverson-Penfield, and K. A. Weigel. In vitro production of bovine embryos using sex-sorted sperm. Theriogenology (accepted). 